\title{
Aloe Gel Enhances Angiogenesis in Healing of Diabetic Wound
}

\author{
Djanggan Sargowo ${ }^{1 *}$, Adeodatus Yuda Handaya ${ }^{2}$, Aris Widodo ${ }^{2}$, Diana Lyrawati ${ }^{2}$, \\ Askandar Tjokroprawiro ${ }^{3}$ \\ ${ }^{1}$ Faculty of Medicine, University of Brawijaya, Jl. Veteran, Malang, Indonesia \\ ${ }^{2}$ Post Graduate Program, Brawijaya Medical School, Jl. Veteran, Malang, Indonesia \\ ${ }^{3}$ Faculty of Medicine, University of Airlangga, Jl. Mayjen Prof. Dr. Mestopo No. 47, Surabaya, Indonesia \\ ${ }^{*}$ Correspondence: djanggan@yahoo.com
}

\section{Abstract}

$\mathrm{B}$ ACKGROUND: Diabetic micro and macroangiophathy lead to the incident of diabetic foot ulcers characterized by an increased number of circulating endothelial cells (CECs) and decreased function of endothelial progenitor cells (EPCs). This fact is correlated with ischemia and diabetic wound healing failure. Aloe vera gel is known to be able to stimulate vascular endothelial growth factor (VEGF) expression and activity by enhancing nitric oxide (NO) production as a result of nitric oxide synthase (NOS) enzyme activity. Aloe vera is a potential target to enhancing angiogenesis in wound healing.

OBJECTIVE: The objective of this study was to explore the major role of Aloe vera gel in wound healing of diabetic ulcers by increasing the level of EPCs, VEGF, and endothelial nitric oxide synthase (eNOS), as well as by reducing the level of CECs involved in angiogenesis process of diabetic ulcers healing.

METHODS: The experimental groups was divided into five subgroups consisting of non diabetic wistar rats, diabetic rats without oral administration of aloe gel, and treatment subgroup (diabetic rats) with 30,60 , and 120 $\mathrm{mg} /$ day of aloe gel doses for 14 days. All subgroups were wounded and daily observation was done on the wounds areas. Measurement of the number of EPCs (CD 34), and CECs (CD45 and CD146) was done by flowcytometry, followed by measurement of VEGF and eNOS expression on dermal tissue by immunohistochemical method on day
0 and day 14 after treatment. The quantitative data were analyzed by One-way ANOVA and Linear Regression, with a confidence interval 5\% and significance level $(\mathrm{p}<0.05)$ using SPSS 16 PS software to compare the difference and correlation between wound diameters, number of EPCs and CECs as well as the levels of VEGF and eNOS.

RESULTS: The results of this study showed that aloe gel oral treatment in diabetic wistar rats was able to accelerate the wound healing process. It was shown by significant reduction of wound diameter $(0.27 \pm 0.02)$; the increased number of EPCs (13.75 \pm 1.63$)$; elevated levels of VEGF $(34,67 \pm 5,03)$ and eNOS $(42,00 \pm 1,00)$; and the decreased number of CECs $(0.42 \pm 0.57)$, respectively ( $<<0.05)$. On the other hand, the wound diameter and eNOS indicators showed significant differences at the dose of $60 \mathrm{mg}$, while the number of EPCs and CECs and the level of VEGF showed significantly different results at a dose of 120 $\mathrm{mg}$. Aloe gel oral therapy showed a positive indication of wound healing acceleration at the optimum dose range 60$120 \mathrm{mg}$ a day.

CONCLUSIONS: Aloe gel is potential to be a herbal therapy candidate for diabetic wound healing through enhancing EPCs homing, decreasing the CECs number, and stimulating the increase of VEGF and eNOS levels, hence proving to be a dominant factor in the angiogenesis process.

KEYWORDS: aloe gel, diabetes, wound healing, angiogenesis

Indones Biomed J 2011 ; 3 (3) ; 204-215 


\section{Introduction}

Diabetes mellitus (DM) is a metabolic disease that occurs in almost all countries around the world. The incidence of DM continues to experience significant increase. In 2003, diabetes affected 197 million people worldwide and was expected to rise more than $50 \%$ in 2010 . The figure is predicted to be 333 million by 2025 or $6.3 \%$ of the total world population. Some $77 \%$ is predicted to occur in developing countries (1). According to WHO, Indonesia has the fourth largest number of diabetics in the world, from 5.6 million in 2000 to 14 million diabetic patients in 2006. In 2025 Indonesia's prevalence of DM is predicted to be $6.5 \%$. According to International Diabetes Federation(IDF), the number of DM cases among people 20-79 years old in Indonesia is as many as 7 million cases. Furthermore, in 2010 Indonesia has the ninth highest rate of diabetic cases among 10 countries in the world and is predicted to be the sixth in 2030 with 12 million of diabetic cases (2).

Complications of DM lead to the emergence of macroangiopathy and microangiopathy disorders and neuropathy, which further cause interference of angiogenesis process, epithelialization, deposition of collagen and some other essential processes in wound healing stages. Failure of diabetic ulcers healing occurs due to disruption of a number of processes in the stages of wound healing. The process of inflammation, cell proliferation, cell migration, vascular permeability and angiogenesis are due to deficiency of growth factors and proangiogenic cytokines, matrix deposition and tissue remodeling $(3,4)$.

Endothelial progenitor cells (EPCs) play an important role in reendothelialization of blood vessel damage caused by ischemia. EPCs potentially contribute to endothelial repair by homing into the damaged endothelial and are able to maintain endothelial integrity. EPCs dysfunction is closely linked with the incidence of vascular ischemia (5).

Decrease in the number and function of EPCs is associated with the pathogenesis of early vascular complications of diabetes of both type 1 and 2. Increased oxidative stress (increased reactive oxygen species/ROS) due to chronic hyperglycemia via activation of four major pathways of diabetic complications also affects the expression and phosphorylation of eNOS. eNOS is known to be important for the survival, migration, and angiogenesis of EPCs or endothelial cells. NO produced by eNOS activity starts mobilizing EPCs from the bone marrow through nitrosylation and increased expression of $\operatorname{VEGF}(6)$.

In normal individuals, the number of circulating endothelial cells (CECS) is low. The number of CECs will increase in case of endothelial cell injury, as in the case of microbial infection that triggers diabetes mellitus/ DM. Although there is no real evidence that CEC with endothelial damage is associated with elevated level of CEC in blood flow, result of a previous study has found that patients with type 1 diabetes have significantly different number of circulating CECs as compared with normal individuals (7).

Management of diabetic ulcers needs to be done in a comprehensive manner through efforts to cope with the comorbid disease and by reducing the load pressure (off loading) in order to keep the wound moist (moist), treating the infection, debridement, revascularization and elective surgery as well as prophylactic, curative or emergency measures. One of the herbal ingredients that has great potential to cure diabetic wounds is Aloe vera.

Aloe vera is a plant that is easy to find and contains bioactive ingredients. Aloe vera therapy has been known to be applied in various diseases, especially in wound healing. Aloe vera gel has the capacity as an immunomodulator and a source of nutrients that likely increase the rate of wound healing. Aloe gel is able to control the inflammatory phase as well as provide nutrients supply to the wound so it can immediately complete the process of wound healing.

Recent researches on the clinical use of Aloe gel have shown that it has an immunomodulatory effect, can balance blood glucose and minimize pain. Only in the group with aloe gel treatment did it show an increase in arteriolar diameter leading towards normal conditions. Wound areas given aloe gel treatment showed better result as compared with the negative control (8). Gel penetration into the tissue network will reduce inflammation and increase blood supply by inhibiting the synthesis of a potent vasoconstrictor thromboxane $A_{2}$ (9). Previous studies have also reported that aloe gel contains Acemannan, a potential bioactive substance $(10,11)$.

Acemannan, as one of the substances in aloe polysaccharide gel, at a dose of $20 \mathrm{mg} / \mathrm{mL}$ was able to stimulate wound healing speed and was capable of stimulating cellular proliferation, migration and cytokine production. Acemannan has the capability to stimulate oxygen consumption, increase angiogenesis and increase synthesis of collagen in the wound area (12). Oral administration of Acemannan accelerates wound healing by inducing fibroblast proliferation and stimulate expression of KGF-1 and VEGF. Acemannan has the ability to stimulate hematopoiesis and antioxidant effects. 
Acemannan also is able to reduce inflammation through the synthesis of prostaglandins and increased infiltration bf leukocytes $(10,11)$.

Based on some of the above facts, further research is needed on the potential of the active ingredients of Aloe vera as a candidate of therapeutic herbal healing of diabetic wounds. This study was conducted to prove that administration of Aloe gel herbal could accelerate wound healing in diabetic animal models by increasing the number of EPC and decreasing circulation level of CECs.

\section{Methods}

\section{Animal Preparation}

Rats used in this experiment were 2 month old male wistar strains with body weight $150-200 \mathrm{~g}$. Normal rats (negative control) were wounded in the dermal area and subsequently injected with $\mathrm{pH} 7,4 \mathrm{PBS}$. Next, the normal rats group was treated with aloe gel orally 30,60 , and 120 mg per day, respectively. Experimental inducted diabetic rats (positive control) were prepared by injecting them intraperitoneally with Streptozotocin (STZ) $60-70 \mathrm{mg}$ / $\mathrm{dL}$. These rats were considered to have diabetes if their fasting blood glucose level reached $200-300 \mathrm{mg} / \mathrm{dL}$ after 3 days of STZ treatment. On day 14 of diabetes, wounds were made on the dermal areas in each rats group, which then were divided into five subgroups: positive control, negative control, and peroral aloe gel treated groups with therapeutic doses of 30,60 , and $120 \mathrm{mg} /$ day for 14 days, respectively.

The rats were anesthetized before being wounded, then treated under a controlled condition during preservation in the experiment cage. The next process was conditioned surgery under sterile condition using ketamine anesthesia (10 $\mathrm{mg} / \mathrm{kg}$ body weight). The rats were anesthetized intraperitoneally with $1 \mathrm{~mL}$ of ketamine hydrochloride $(10 \mathrm{mg} / \mathrm{kg}$ body weight) and their fur was shaved on both sides. A wound area was made by making the outer lines on the back of the rats with methylene blue using a marker or ring-shaped pattern. Each wound diameter $(\varnothing)$ was $2.5 \mathrm{~cm}$ with a depth of $0.2 \mathrm{~cm}$ from the dermal surface made with tweezers, scalpel number 15 , and scissors with pointed tips. The wounds' diameter and sterility were maintained by sewing on an antibiotic tool and compressed with a gauze cover with $0.9 \% \mathrm{NaCl}$ (13).

\section{Extraction and Purification of Aloe vera Gel (Aloe vera Linn.)}

Mature healthy leaves of Aloe vera were collected from Aloe vera farming in Malang, East Java. These leaves were brushed and cleaned with nontoxic disinfectant (calcium hypochlorate $98 \%$ ), then rinsed with aquadest and dried on their surface. Aloe vera leaves were cut and stored in a suitable container perpendicularly to the bottom of the container and let the exudate of the leaves flow out for about 30-60 minutes. The bases of the leaves were then cut into about $1 \mathrm{~cm}$ in size, peeled thoroughly to break the outside part of the parenchyme cells. The leaf pulps (gel) then were rinsed with flowing water several times, peeled and chopped for further processing with a juicer. The washing step was done to rinse out dirt and bacteria on the aloe vera leaves surfaces. The obtained Aloe vera juice was added with ethanol $96 \%$ with 1:4 ratio, in this case $50 \mathrm{~mL}$ of Aloe vera juice was added with $200 \mathrm{~mL}$ ethanol $96 \%$. Aloe vera and ethanol mixture were stirred for 10 minutes in maximal temperature of $30^{\circ} \mathrm{C}$. The mixture then was left for 10 hours to let the precipitation process begin. The obtained precipitation was separated using inhalator filter, and the sediment dried with a vacuum dryer under a temperature of $50^{\circ} \mathrm{C}(14)$.

\section{Wound Healing Mesurement}

The measurement of wound healing area was done by drawing it on a transparent plastic sheet, described it onto the graph paper by means of a carbon paper and assessed after 14 days post treatment.

\section{Flowcytometry Measurement of CEC and EPC}

Peripheral blood samples were obtained using a syringe. The blood was incubated with anti-CD146-FITC, then flown and isolated with flowcytometry. Cells were gathered and centrifuged at $2500 \mathrm{rpm}, 4^{\circ} \mathrm{C}$, for 5 minutes. Cell sedimentation was washed twice with phosphate buffer saline (PBS) then shaken slowly. Cell sedimentation was incubated with anti-CD146-FITC and anti CD45-PE (1:100) in $100 \mu 1$ PBS for 30 minutes at room temperature. Finally, the mixture was diluted until $1 \mathrm{~mL}$ and read by flowcytometry (FACS Callibur, BD).

\section{Immunohistochemistry Measurement of VEGF and eNOS}

After staining with immunohistochemical technique, preparations of each treatment and repetition was photographed with Olympus Brand photomicrosope with $400 x$ magnification. The percentages of cells that expressed VEGF and eNOS protein in the rats dermal tissue slice preparations from all treatment groups were calculated from the photo results. 


\section{Results}

The negative control group of non-diabetic wistar rats and The negative control group of non-diabetic wistar rats and positive control of diabetic rats (glucose $200-300 \mathrm{mg} / \mathrm{dL}$ ) showed that aloe gel significantly affected the healing of diabetic wounds $(\mathrm{p}>0.05)$ based on the diameter of the wound, and also affected the number of EPC and CEC as well as the levels of VEGF and eNOS. Aloe vera gel peroral therapy for 14 days showed changes in significant values (positive trends) of all indicators.

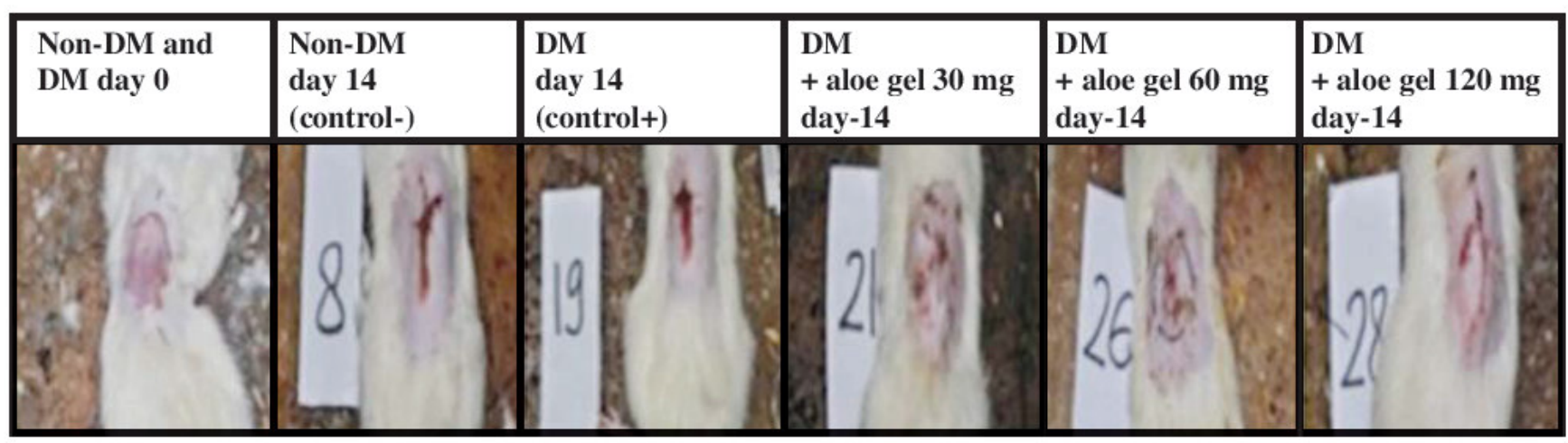

Figure 1. Results of the observation on the wound areas in Normal and DM rats treated with Aloe gel.

Description: The surfaces of wounds at day- 0 was created with a diameter of $2.5 \mathrm{~cm}$. Measurement of wound area at day- 14 in the administration of $60 \mathrm{mg}$ group $(0.27 \pm 0.02)$ showed narrowing of the wound area which was significantly different from those of the negative control (1.10 \pm 0.14$)$ and positive control $(1.19 \pm 0.08)$.

According to Figure 1, after extensive wound measurements using millimeter papers, it showed that there was a significant difference in the average value of the total wound area in each treatment group. In the DM group rats with 30 and $120 \mathrm{mg}$ treatment dose of Aloe gel showed significantly different results as compared to the control group on the average area of the same wound. While the DM group that was treated with $60 \mathrm{mg}$ aloe gel showed the most significant result as compared to the control group.
Based on statistic analysis by one-way Anova, it was shown that wound area width demonstrated a differently significant result $(\mathrm{p}=0,000)$ according to the measurement results with graphic paper and computer analysis. The 60 $\mathrm{mg} / \mathrm{kg}$ body weight-treated group $(0.27 \pm 0.02)$ showed a significantly different result from the negative control $(1.10 \pm 0.14)$ with a confidence level $(\mathrm{p}<0,05)$. The average values of diversity are shown in Table1.

\section{Table 1. The mean value of wound size Measurements based on the results}

\begin{tabular}{lll}
\hline Treatment Group & $\mathbf{n}$ & Mean \pm SD \\
\hline Negative control & 3 & $1.10 \pm 0.14^{\mathrm{a})}$ \\
Positive control & 3 & $1.19 \pm 0.08^{\mathrm{a})}$ \\
DM dose of $30 \mathrm{mg}$ & 3 & $0.32 \pm 0.01^{\mathrm{b})}$ \\
DM dose of $60 \mathrm{mg}$ & 3 & $0.27 \pm 0.02^{\mathrm{b})}$ \\
DM dose of $120 \mathrm{mg}$ & 3 & $0.41 \pm 0.02^{\mathrm{b})}$
\end{tabular}

Description: the same notation indicates not significantly different while different notations indicate significantly different. 
EPCs Measuring with Flowcytometric Method

According to EPCs measurements by flowcytometry, we found the average value comparison of the number of EPCs in all treatment groups as shown in Figure 2.

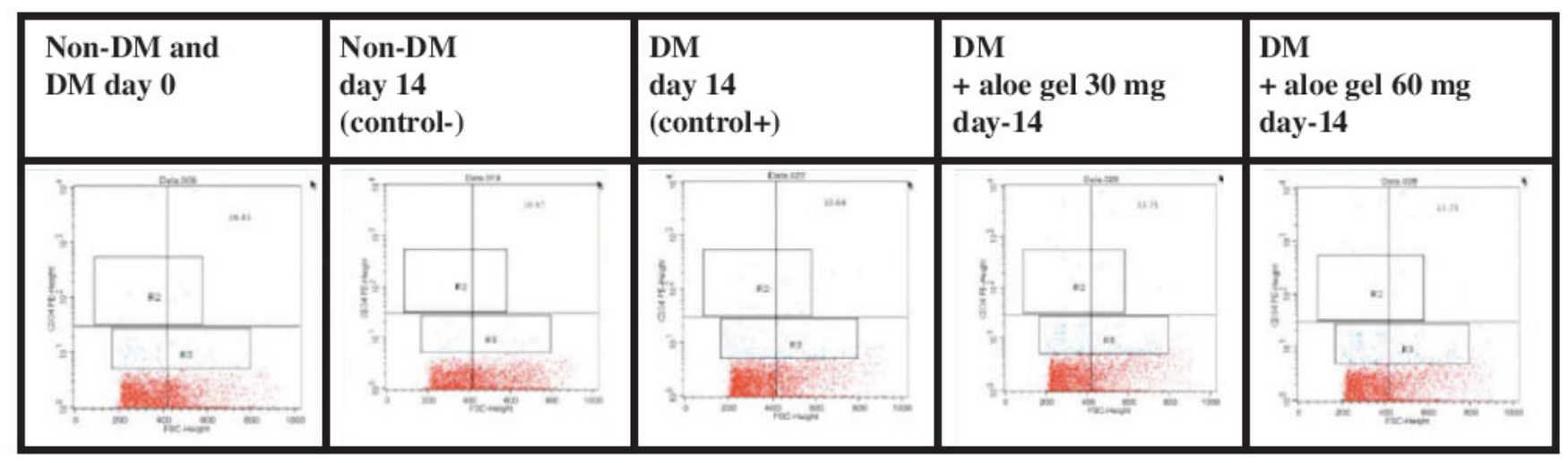

Figure 2. Calculated number of EPCs marker, CD 34, using flowcytometry.

Based on the statistic evaluation with one-way Anova, the number of EPCs showed different results but not statistically significant. The $120 \mathrm{mg} / \mathrm{kg}$ body weighttreated group $(13,75 \pm 1,63)$ showed an obviously different results from those of the negative control $(16.88 \pm 0.59)$ and the positive control $(10.47 \pm 1.14)$. The average results of diversity are shown in Table 2.

\section{Table 2. The mean number of EPC based measurement}

\begin{tabular}{lll}
\hline Treatment & $\mathbf{n}$ & Mean \pm SD \\
\hline Negative control & 3 & $16.68 \pm 0.59^{\mathrm{a})}$ \\
Positive control & 3 & $\left.10.47 \pm 1.14^{\mathrm{a}}\right)$ \\
DM Dose of $30 \mathrm{mg}$ & 3 & $10.64 \pm 9.34^{\mathrm{b}}$ \\
DM Dose of $60 \mathrm{mg}$ & 3 & $12.11 \pm 1.16^{\mathrm{b}}$ \\
DM Dose of $120 \mathrm{mg}$ & 3 & $13.75 \pm 1.63^{\mathrm{b}}$ \\
\hline
\end{tabular}

Description: the same notation indicates not significantly different while different notations indicate significantly different. 
Calculation of VEGF expression and level by immunohistochemistry

Based on the calculation results obtained by the method of comparative pictures by Immunohistochemistry, the average values of VEGF expressions between the treatment groups were found as shown in Figure 3.

\begin{tabular}{|c|c|c|c|c|}
\hline $\begin{array}{l}\text { Non-DM and } \\
\text { DM day } 0\end{array}$ & $\begin{array}{l}\text { Non-DM } \\
\text { day } 14 \\
\text { (control-) }\end{array}$ & $\begin{array}{l}\text { DM } \\
\text { day } 14 \\
\text { (control+) }\end{array}$ & $\begin{array}{l}\text { DM } \\
+ \text { aloe gel } 30 \mathrm{mg} \\
\text { day-14 }\end{array}$ & $\begin{array}{l}\mathrm{DM} \\
+ \text { aloe gel } 60 \mathrm{mg} \\
\text { day-14 }\end{array}$ \\
\hline 40 & $\infty 2$ & & 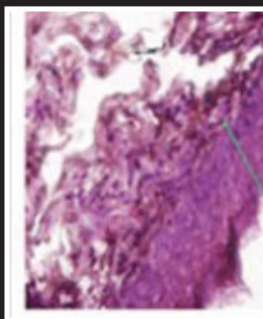 & \\
\hline
\end{tabular}

Figure 3. Result of expression of VEGF using immunohistochemistry on rats.

Description: calculated expression of VEGF by immunohistochemistry showed the group with a target dose of $60 \mathrm{mg}$ of epithelial cells in stratum basale cells expressed more than other dose groups.

The photo results in Figure 3 show that the control group (DM rats) has higher percentage of cells than the treatment group which presents expression of VEGF. In the $60 \mathrm{mg}$ Aloe vera-treated group, the expression of VEGF was significantly different from the control group. According to Figure 3, it appears that the expression of VEGF was increased in all Aloe vera-treated groups compared to the positive controls. However, one-way ANOVA test showed that expression of VEGF had no significantly different results $(\mathrm{p}=0.676)$ based on the measurements by immunohistochemical method. Comparison of VEGF expressions based on the average percentages of cells that expressed VEGF between groups is shown in Table 3.

Table 3. The mean expression of VEGF using immunohistochemical method

\begin{tabular}{lll}
\hline Treatment Group & $\mathbf{n}$ & Mean \pm SD \\
\hline Negative control & 3 & $24.67 \pm 2.00^{\text {a) }}$ \\
Positive control & 3 & $25.33 \pm 4.51^{\text {a) }}$ \\
DM Dose of $30 \mathrm{mg}$ & 3 & $28.33 \pm 5.86^{\text {a) }}$ \\
DM Dose of $60 \mathrm{mg}$ & 3 & $34.67 \pm 5.03^{\mathrm{a}}$ \\
DM Dose of $120 \mathrm{mg}$ & 3 & $25.67 \pm 4.73^{\mathrm{a}}$ \\
\hline
\end{tabular}

Description: the same notation indicates not significantly different while different notations indicate significantly different. 


\section{Calculation of eNOS expression}

by immunohistochemistry

Based on the calculation results obtained by immuno- histochemical method, pictures of comparison of the average value of the expression of eNOS between the treatment groups are shown in Figure 4.

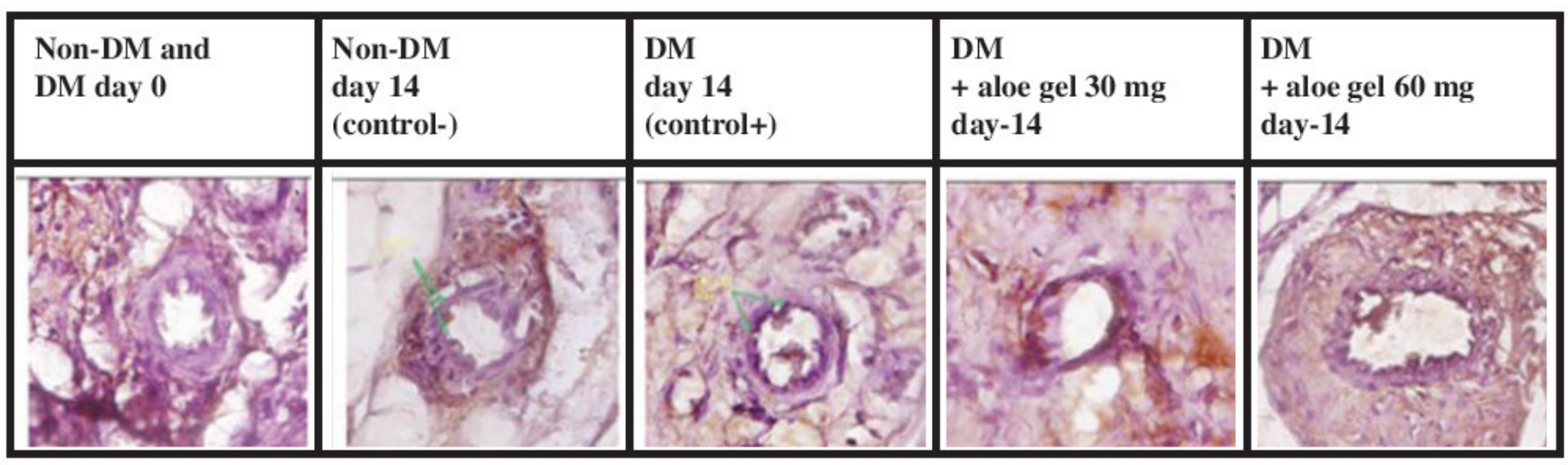

Figure 4. Result of expression of eNOS using immunohistochemical methods on rats wound.

Description : calculation by immunohistochemistry showed that the $60 \mathrm{mg}$-treated group had increased eNOS expression of epithelial cells in stratum basale cells compared with the other dose groups.

One-way ANOVA analysis showed that expression of eNOS gave significant results $(\mathrm{p}=0.000)$ based on the immunohistochemical methods. The results by immunohistochemical staining (Figure 4) showed differences in the percentages of cells that expressed eNOS. Based on Figure 4, it appears that the expression of
eNOS increased in the two respective treatment groups of $30 \mathrm{mg}, 60 \mathrm{mg}$, as evidenced by the values of percentage that increased compared to the control cells. Comparison of eNOS expressions based on the average color intensity of eNOS expression between groups is shown in Table 4.

Table 4. The mean expression of eNOS using Immunohistochemical method

\begin{tabular}{lll}
\hline Treatment Group & $\mathbf{n}$ & \\
\hline Negative control & 3 & $24.67 \pm 1.73^{\mathrm{b})}$ \\
Positive control & 3 & $30.67 \pm 1.08^{\mathrm{a})}$ \\
DM Dose of $30 \mathrm{mg}$ & 3 & $30.00 \pm 1.00^{\mathrm{a})}$ \\
DM Dose of $60 \mathrm{mg}$ & 3 & $34.33 \pm 2.08^{\mathrm{a}}$ \\
DM Dose of $120 \mathrm{mg}$ & 3 & $42.00 \pm 1.00^{\mathrm{b}}$ \\
\hline
\end{tabular}

Description: the same notation indicates not significantly different while different notations indicate significantly different. 
To assess the relationships between several variables in previous studies, we did a linear regression test and obtained the results of path analysis as shown in Figure 5 .

Linear Regression based on the test results to illustrate the path analysis showed a strong mutual relationship in the pathway wound healing mechanisms of DM associated with the role of EPCs, CEC, VEGF, and eNOS that affected the diameter of the wound as an indicator morphology of the diabetic wound healing process. From the regression test results it appeared that there was a strong relationship between VEGF on EPC numbers $(\mathrm{R} 2=0.119)$, levels of eNOS on wound diameter $(\mathrm{R} 2=0.208)$, eNOS to total $\mathrm{CEC}(\mathrm{R} 2=0.357)$, VEGF to the wound diameter $(\mathrm{R} 2=$ $0.038)$, and the EPC to the wound diameter $(\mathrm{R} 2=0.079)$.

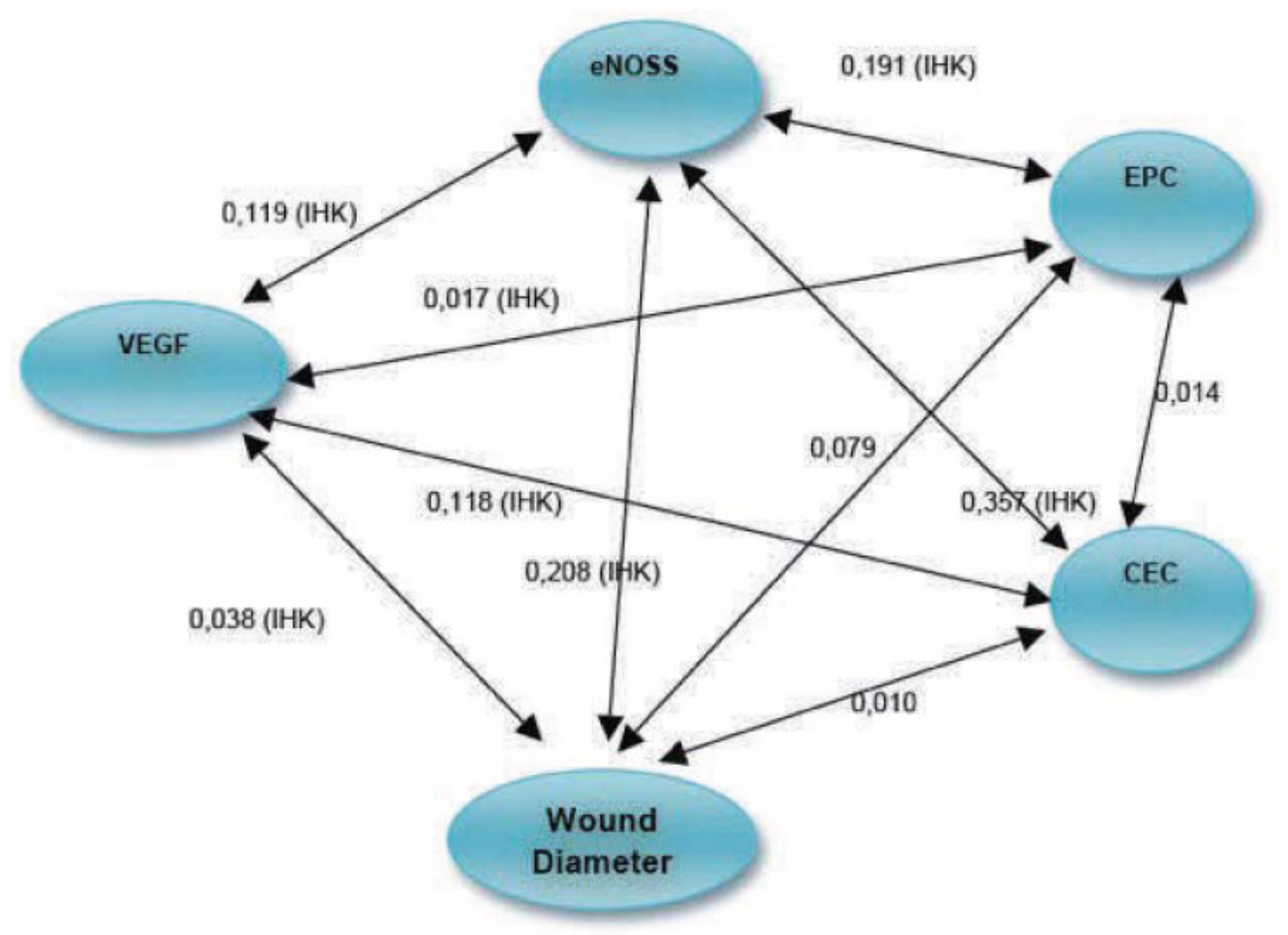

Figure 5. Path Analysis.

\section{Discussion}

\section{The Corellation of Aloe Gel Administration and Cutaneous Wound Diameter}

The main results of the experiment of diabetic wistar rats wounds that were treated with aloe gel orally showed improvements in the wound diameter compared to the control group. These results were evidenced by the presence of VEGF, increased level of eNOS, increased number of EPC, and reduced CEC level, which confirmed the important role of herbal aloe gel in the angiogenesis of diabetic wound healing. From previous experiments, it was reported that anti-inflammatory effect and wound healing stimulator from aloe gel were capable of providing significant effect as Allowable Daily Intake (ADI) and Upper Intake Level (UIL) in the range of $60-120 \mathrm{mg} / \mathrm{kg}$ body weight, with the assumption that the administration was done for 1 month $(15,16)$.

Aloe gel administration to wounds of diabetic wistar rats showed significant wound improvement with decrease of the wound diameter with aloe gel administration with a dose range of $60-120 \mathrm{mg} / \mathrm{kg}$ body weight as compared to the positive control group. This acceleration of wound diameter change was probably 
due to polysaccharide-containing aloe gel substance which accelerates fibroblast proliferation, hyaluronic acid production, and hydroxypylene. These results indicate that aloe gel polysaccharide has a central role in remodeling extracellular matrix during wound healing period (17). Micronutrient therapy and Aloe vera topically can enhance tissue regeneration process. The mannose-6-phosphate content in Aloe vera is considered to be able to bind to fibroblast receptor and activate cell proliferation (18).

The other effect of aloe gel administration was to enhance wound diameter reduction through stimulating wound healing capability as compared to the positive control group. Moreover, aloe gel stimulated immune system by increasing neutrophils, macrophage, and fibroblast cells quantity in the wound cleft. This is parallel to the results of previous experiments in which $30 \mathrm{~g}$ of aloe gel administered twice a day was able to enhance wound healing progression in normal rats (19). Wound diameter reduction was also observed in wounds treated with aloe gel among experimental rats possibly through increasing collagen and glycosaminoglycan synthesis (20).

Aloe vera is effective in accelerating wound contraction either with oral administration or topical application. Wound contraction is a crucial factor in healing process resulted from wound healing shift to the middle. Other experiment reports that orally administered Aloe vera accelerates wound healing in acute radiation exposed rats models.

The number of EPCs and CECs underwent such a significant change in the $120 \mathrm{mg} / \mathrm{kg}$ body weight per day-aloe gel treated group. This result showed that oral therapy of aloe gel was highly potent in accelerating wound healing through promoting EPCs mobilization, its lifetime in peripheral circulation in diabetic condition, and also neovascularization by stabilizing the role of EPC in cutaneous wound vascular area of the diabetic rats. On the other hand, it enhanced EPCs number accompanied by cellular marker of another vascular dysfunction, CECs. In this experiment, $60-120 \mathrm{mg} / \mathrm{kg}$ body weight of treatment with aloe gel proved to be capable of reducing the number of CECs in diabetic rats significantly. Wound healing acceleration in this experiment was also supported by the significant increase of EPCs number in the 120 $\mathrm{mg} / \mathrm{kg} \mathrm{BW}$-treated group and obviously reduced CEC number in circulation in the $60 \mathrm{mg} / \mathrm{kb} \mathrm{BW}$-treated group. Neovascularization failure in diabetic wound makes it possible for increasing eNOS phosphorylation in the bone marrow after aloe gel treatment.

Generally in the case of diabetic healing failure, the failure may be due to reduction of granule tissue and increase of apoptosis due to circulating EPCs level. In diabetic rats, circulated EPCs did not change until 4 weeks after experimental diabetes or skin wound was carried out. After 4 weeks, it was observed that there was a significant reduction in the EPCs number in the diabetic rats which was shown by the increase of apoptosis and reduction of proliferation on the wound areas in the diabetic rats. It was concluded it was closely related to the damage in recruiting, lifetime, and bone marrow-derived progenitor cells. Aloe gel treatment is expected to be capable of restoring EPC homing and progenitor cells lifetime in order to increase wound healing in diabetic tissue. On the other hand, it is mentioned that progenitor cells dysfunction in diabetic individuals influence vasculogenesis process (adhesion, proliferation, migration, and tube formation failure) (21)

Results of the most recent experiments indicate a possibility that in diabetic animals or humans, wound healing failure is extremely related to the failure of migration in several vasculogenetic progenitors in the circulation (22). However, in this experiment Aloe gel treatment to diabetic rats was capable of keeping EPCs capability to migrate and accelerate wound healing as shown by acceleration of wound diameter narrowing. It is true that until today, whether the decrease of these vasculogenic progenitor cells which also decrease in type 1 diabetic rats models is involved in the pathogenesis of wound healing failure, remains to be poorly understood. However, result of the present study proves that in wounded type 1 diabetic rats models, significantly increased EPCs number has occurred as compared to the group given oral therapy with aloe gel in a range of dose of $60-120 \mathrm{mg} / \mathrm{kg}$ BW.

On the other hand, it is known that type II diabetes animal models have significantly decreased progenitor cells during homeostasis process after cutaneous ischemia takes place or wound is formed (22). Generally, as shown in this experiment, there was a correlation between increased level or number of stem cells (vasculogenic progenitor) and the significant improvement of wound reepithelialization in diabetic animal models. EPCs number and function change occurs in DM and wound healing (23).

Previous studies stated that oxidative stress resulted from high glucose exposure in circulation would trigger EPCs dysfunction (24). The studies assumed that DM induced EPCs destruction during its route when migrating from bone marrow. A speculation also arised that increased number of EPCs released from the bone marrow to the circulation that occurs in diabetic individuals is caused by high number of dead EPCs along its vascular route. Diabetic EPCs also show failure of integrative ability in neovascularization in ischemic organ which undergoes 
decline of reendothelialization function after vascular damage has occurred. Oral administration of aloe gel has proved that it has a capability of increasing the number of circulating EPCs through maintaining these surviving progenitor cells in the vasculars in the wound areas to begin neovascularization. Aloe gel therapy also stimulates repair and re-endothelialization in the wound area.

In diabetic wistar rats wounds, EPCs level increased on the $14^{\text {th }}$ day after aloe gel administration as compared to the control group, by expressing CD34 antigen marker as shown with flowcytometry. Clinically, EPCs is capable of improving disease condition, which commonly begins with endothelial cells damage, either anatomically, structurally or functionally, through neovascularization mechanism. Results of previous experiments have confirmed that in the bone marrow and peripheral blood flow there are cells that are able to multiply and differentiate to become endothelial cells that can improve ischemic tissue caused by damaged blood vessel wall.

Aloe gel therapy is predicted to be able to accelerate endothelial cells line to stick to the basal membrane. The loss of blood flow cells is very low with a consequence that they will be destructed by the reticuloendothelial system. Aloe gel can suppress pathophysiologic process in diabetic rats which causes release of endothelial cells to the basal membrane and this will result in increased CECs number in blood flow.

In diabetic wistar rats, the level of CECs declined on $14^{\text {th }}$ day after aloe gel administration as compared to the EPCs control by CD45 and CD146 antigen marker expression. On the other hand, in normal individuals the number of CECs is low. The number of CECs will increase if there is endothelial cell injury. Previous experiments have found that in DM patients as compared to normal ones, there was such a significant difference in the number of circulating CECs (7). Furthermore, it is understood that there was increased VEGF level in the $120 \mathrm{~kg} / \mathrm{mg}$ BW-treated group, followed by increased eNOS level in the $60-120 \mathrm{mg} / \mathrm{kg}$ BW-treated group compared to the control by ELISA examination. These data indicate that oral administration of aloe gel on diabetic animal models might be able to enhance wound healing by increasing the levels of EPCs and VEGF and by activating NO synthesis enzyme which became the downstream signal of angiogenesis molecular pathway.

Aloe vera treatment showed positive effect to wound healing after $7^{\text {th }}-14^{\text {th }}$ day from the beginning of the wound (25). Aloe gel is suspected to stimulate phagocytosis activity and induce NO production, enhance synthesis, cross linking and collagen maturation, stimulate cell proliferation, stimulate fibroblast function and proliferation, inhibit arachidonic acid oxidation, possess anti-inflammatory effect, reduce TNF- $\alpha$ level and antioxidant activity (26). Besides, oral aloe gel therapy which contains $\beta$-Sitosterol also enhances angiogenesis related protein expression, which is VEGF (27).

Aloe gel treatment in our present study was capable of accelerating NO production, so it would accelerate eNOS enzyme in endothelial as well as VEGF activity to enhance diabetic wound healing angiogenesis. Aloe gel stimulates eNOS dominant role and NO production in the endothelial by means of two processes, namely angiogenesis (new blood vessel development from the already existing blood vessel) and vasculogenesis (de novo blood vessel formation from progenitor cells) (28). Moreover, this experiment showed positive effect where oral aloe gel therapy may have increased eNOS level. eNOS is the central factor for EPCs mobilization either in human or diabetic animal model. Aloe gel is predicted to be able to suppress some molecules involved in inhibition of eNOS activity. It is in accordance with a previous experiment where increase of dimethyl-arginine as NOS endogen inhibitor in DM case became supporting factor in EPCs function failure in diabetic individuals. Protein glycoloxidation is suspected to cause decline of EPCs capability. Diabetic EPCs also release some unidentified factor which accelerates vascular endothelial cell ageing (24). That is why this aloe gel therapy is expected to be an effort for damaged vascular improvement by mobilizing EPCs for re-stabilizing the damaged vascular function caused by DM complication.

The fact that aloe gel can increase VEGF level in wound area gives good effect to acceleration of diabetic wound healing where reduction of VEGF production and angiogenesis process contribute to tissue improvement in diabetic patients. VEGF expression is strongly induced by hypoxic condition through transcription factor hypoxia inducible factor- 1 . In diabetic rats, VEGF topical application performs acceleration of skin wound improvement as well as mobilization and recruiting vascular progenitor cells (3). With the stimulation effect to VEGF activity, aloe gel is predicted to be able to accelerate wound healing by increasing growth factor local regulation., which is important for tissue repair and will systematically mobilize precursor cells from the bone marrow, especially progenitor cells that contribute to blood vessel formation that will accelerate wound repair (29).

The other factor is aloe gel can probably regulate proteolysis effect which is reported to begin VEGF activity reduction in diabetic wound $(30,31)$. Aloe gel performs stimulation effect to wound healing involving cells, such as keratinocyte and macrophage, which play an important 
role in this growth factor during normal wound healing (32) through accelerating VEGF as growth factor with proangiogenic effect by increasing cellular proliferation $(33,34)$

Other thing to be considered is the possibility that in this experiment aloe gel might be able to promote angiogenesis by increasing the PI3K/Akt, MAPK, ERK, and eNOS/NO signal pathway. PI3K/Akt pathway activation stimulates eNOS activation through phosphorylation in serine 1177 that causes stimulation of NO production. Aloe gel might also be able to cause decline of PI3K/Akt pathway inhibition or eNOS activity that will inhibit growth factor activity and angiogenesis mediating cytokine. Aloe gel can accelerate wound healing process with probability of promoting PI3K/Akt/eNOS signaling pathway activation which play a crucial role in angiogenesis. The pathway of ERK $1 / 2$ has an important role in growth mechanism, differentiation, cell survival, and death during vascular protection process as well as angiogenesis in wound healing. It is parallel to the result of previous experiments where Korean red ginseng extract exposure under HUVECs culture can activate Akt, ERK and eNOS pathways as well as increasing NO production, an angiogenesis-related process (35). Other probability is aloe gel posseses a potential to regulate cytosolic calcium level. Even though eNOS activity can be accelerated by VEGF that will accelerate Akt and $\mathrm{PKC}$ pathway activation, the main stimulus for NO production will be enhanced if it is induced by increased cytosolic calcium level $(36,37)$. Therefore, there is a strong prediction that aloe gel has angiogenic effect mediated by $\mathrm{NO}$ as the resut of eNOS induction in vascular cell (38).

If aloe gel can stabilize VEGF activity, then in the other part expression and phosphorylation of eNOS mentioned are important for survival, migration, and angiogenesis of EPCs or endothelial cells will be stable. The NO resulted from eNOS activity begins EPCs mobilization from the bone marrow through upregulation of nitrosylation and VEGF expression (6)

\section{Conclusion}

The conclusions of this experiment include the fact that aloe gel oral therapy (optimal dose range $60-120 \mathrm{mg} / \mathrm{kg}$ BW a day) correlates with the wound healing in diabetic wistar rats, as evidenced by the presence of wound diameter improvement in positive control and treatment group as compared to the negative control. Furthermore, aloe gel has a potential capability of being a candidate of diabetic wound healing herbal therapy through acceleration of EPCs homing, reducing CECs number, accelerating VEGF and eNOS pathways, and increasing neovascularization process in the diabetic dermal area wound healing.

\section{Acknowledgement:}

We thank Mr. Satuman for the contribution and support for the study.

\section{References:}

1. Goycheva P, Gadjeva V, and Popov B. Oxidative Stress and Its Complication in Diabetes. Trakia Journal of Sciences 2006; 4: 1-8.

2. Tjokroprawiro A. Clinical Staging of Hyperglicemia diabetic vascular complication. Endocrine and Diabetes ForumRegional Sumatera-2010-3, 30-859-K.

3. Pradhan L, Nicholas DA, Frank WL, Aristidis V. Molecular Targets for Promoting Wound Healing in Diabetes. Recent Patents on Endocrine, Metabolic \& Immune Drug Discovery 2007; 1: 1-13.

4. Ralf L, Gregory S, Hendrik L. Proteases and the Diabetic Foot Syndrome: Mechanisms and Therapeutic Implications. Diabetes Care 2005; 28: 461-71.

5. Cindy JM, Loomans, Eelco JP, de Koning, Frank JTS, Maarten $\mathrm{BR}$, et al. Endothelial Progenitor Cell Dysfunction A Novel Concept in the Pathogenesis of Vascular Complications of Type 1 Diabetes. Diabetes 2004; 53: 195-9.

6. Chen,Yung-Hsiang, Shing-Jong Lin, Feng-Yen Lin, Tao-Cheng Wu, Chen-Rong Tsao, Po-Hsun Huang, et al. High Glucose Impairs Early and Late Endothelial Progenitor Cells by Modifying Nitric Oxide Related but Not Oxidative StressMediated Mechanisms. Diabetes 2007; 56: 1559-68.

7. McClung JA, Naseer N, Saleem M, Rossi GP, Weiss MB, Abraham NG. Circulating endothelial cells are elevated in patients with type 2 Diabetes independently of $\mathrm{HbA1c}$. Diabetologia 2005; 48: 345-50.

8. Somboonwong J, Thanamittramanee $\mathrm{S}$, Jariyapongskul A, Patumraj S. Therapeutic effects of Aloe vera on cutaneous microcirculation and wound healing in second degree burn model in rats. J Med Assoc Thai 2000; 83: 417-25.

9. Gallagher J, Gray M. Is Aloe vera effective for healing chronic wounds?. J Wound Ostomy Continence Nurs 2003; 30: 6871.

10. Ramamoorthy L, Kemp MC, Tizard IR. Acemannan, a beta$(1,4)$-acetylated mannan,induces nitric oxide production in macrophage cell line RAW 264.7. American Society for Pharmacology and Experimental Therapeutics 1996; 50: 878-84.

11. Hamman JH. Composition and Applications of Aloe vera Leaf Gel. Molecules 2008; 13: 1599-616.

12. Laura K.S. Parnell, MS, Anthony D. Chinnah, and lan R. Tizard. Use of Mouse Footpad Model to Test Effectiveness of Wound Dressings. Diabetes spectrum 2009; 14 (5): 199208.

13. Nayak BS. Cecropia peltata L (Cecropiaceae) Has WoundHealing Potential: A Preclinical Study in a Sprague Dawley Rat Model. LOWER EXTREMITY WOUNDS 2006; 5: 20-26

14. Padmadisastra Y, Sidik, Ajizah. Formulasi Sediaan Cair Gel Lidah Buaya (Aloe vera Linn.) Sebagai Minuman Kesehatan. Simposium Nasional Kimia Bahan Alam 2003; III: 1-13. 
15. Kwack SJ, Kim KB, and Lee BM. Estimation of tolerable upper intake level (UL) of active aloe. Toxicol Environ Health 2009; 72: 1455-62.

16. Jia Y, Zhao G, Jia J. Preliminary evaluation: the effects of Aloe ferox Miller and Aloe arborescens Miller on wound healing. J Ethnopharmacol 2008; 120(2): 181-9.

17. Liu LY, Chen XD, Wu BY, Jiang Q. Influence of Aloe polysaccharide on proliferation and hyaluronic acid and hydroxyproline secretion of human fibroblasts in vitro. Ong Xi Yi Jie He Xue Bao 2010; 8(3): 256-62.

18. Fernanda ASM, Passarini JR, Marcelo AME, Josué SM, Cristina CF, Glaucia MTS. Effects of the application of Aloe vera (L.) and microcurrent on the healing of wounds surgically induced in Wistar rats. Acta Cirúrgica Brasileira 2009; 24 (2): $150-5$

19. Nasrin T, Mir-jamal H, Gholamreza H, Hamideh M, Alireza T, Parisa H. Influence of Aloe vera Gel on Dermal Wound Healing Process in Rat. Toxicology Mechanisms and Methods 2009; 9 (1): 73-7.

20. Jettanacheawchankit $S$, Sasithanasate $S$, Sangvanich $P$, Banlunara W, Thunyakitpisal P. Acemannan Stimulates Gingival Fibroblast Proliferation; expressions of Keratinocyte Growth Factor-1, Vascular Endothelial Growth Factor,and Type I Collagen; and Wound Healing. J Pharmacol Sci 2009; 109: 525-31.

21. Albiero M, Menegazzo L, Boscaro E, Agostini C, Avogaro A, Fadini GP. Defective recruitment, survival and proliferation of bone marrow-derived progenitor cells at sites of delayed diabetic wound healing in rats. Diabetologia 2011; 54(4): 945-53.

22. Oren M T, Jacquelyn C, Robert J A, Christopher C, Clarence D L, Rica T, et al. Decreased Circulating Progenitor Cell Number and Failed Mechanisms of Stromal Cell-Derived Factor-1- $\alpha$ Mediated Bone Marrow Mobilization Impair Diabetic Tissue Repair. Diabetes 2010; 59: 1974-83.

23. Sibal L, Aldibbiat A, Agarwal SC, Mitchell G, Oates C, Razvi S, et al. Circulating endothelial progenitor cells, endothelial function,carotid intima-media thickness and circulating markers of endothelial dysfunction in people with type 1 Diabetes without macrovascular disease or microalbuminuria. Diabetologia 2009; 52: 1464-73.

24. Spinetti G, Nicolle K, Costanza E, Paolo M. Diabetes and vessel wall remodelling: from mechanistic insights to regenerative therapies. Cardiovascular Research 2008; 78: 265-73.

25. Heggers JP, Pelley RP, Robson MC. Beneficial effects of Aloe in wound healing. PHYTOTHER. RES. 1993; 243.

26. Innan A, Meral Ş, Cemile K, Metin E, Cenap D. Effects of Aloe vera on colonic anastomoses of rats. Journal compilation 2007; 427.
27. Choi S,Kim KW, Choi JS, Han ST, Park YI, Lee SK, et al (2002). Angiogenic activity of beta-sitosterol in the ischaemia/ reperfusion-damaged brain of Mongolian gerbil. PlantaMed 2002; 68: 330-5.

28. Duda GD, Dai F, Rakesh KJ. Role of eNOS in neovascularization: NO for endothelial progenitor cells. Trends in Molecular Medicine 2004; 10: 143-5.

29. Stuart E, Joseph EG, Keith GH. Recent advances and emerging treatments. BMJ 2006; 332: 962-5.

30. Saaristo A, Tuomas T, Anniina F, Marika K, Erkki S, Seppo Y, et al. Vascular Endothelial Growth Factor-C Accelerates Diabetic Wound Healing. Am J Pathol 2006; 169: 1080-7.

31. Costanza E, Maria B S, Alessandra P, Gallia G, Luigi M and Paolo M. Nerve Growth Factor Promotes Angiogenesis and Arteriogenesis in Ischemic Hind Limbs. Circulation 2002; 106: 2257-62.

32. Domenica A, Antonino S, Domenico C, Mariarosaria G, Barbara D, Michele C, Valerio T, et al. Inhibition of Lipid Peroxidation Restores Impaired Vascular Endothelial Growth Factor Expression and Stimulates Wound Healing and Angiogenesis in the Genetically Diabetic Mouse. Diabetes 2001; 50: 667-74.

33. Singhan TMK, Cristian Q, Maria J, Rayaz AM, Gerry R. Neurovascular Factors in Wound Healing in the Foot Skin of Type 2 Diabetic Subjects. Diabetes Care 2007; 30: 305862.

34. Young-Kwon H, Bernhard LA, Paula V, Satoshi H, Rainer $\mathrm{K}$, Lawrence $\mathrm{FB}$, et al. VEGF-A promotes tissue repair associated lymphatic vessel formation via VEGFR-2 and the $\alpha 1 \beta 1$ and $\alpha 2 \beta 1$ integrins. The FASEB Journal $2004 ; 10$ : 1096-179.

35. Kim YM, Seung N, Young GY, Hee DH, Young CL, Kwon SH, et al. Water Extract of Korean Red Ginseng Stimulates Angiogenesis by Activating the PI3KJAkt-Dependent ERK1/2 and eNOS Pathways in Human Umbilical Vein Endothelial Cells. Biol. Pharm. Bull 2007; 30: 1674 -1679

36. Dawson NS, David CZ, Mack HW, Harris JG. Signaling pathways mediating VEGF165-induced calcium transients and membrane depolarization in human endothelial cells. The FASEB Journal 2006; 20: 1.

37. Aramoto $\mathrm{H}$, Jerome WB, Peter JP, Robert WH, Walter ND. Vascular endothelial growth factor stimulates differential signaling pathways in the in vivo microcirculation. Am J Physiol Heart Circ Physiol 2004; 10: 1-35.

38. Tanimoto T, Zheng-Gen J, and Bradford C B. Transactivation of Vascular Endothelial Growth Factor (VEGF) Receptor Flk$1 / K D R$ Is Involved in Sphingosine 1-Phosphatestimulated Phosphorylation of Akt and Endothelial Nitric-oxide Synthase (eNOS). The Journal of Biological Chemistry 2002; 277(45): 42997-3001. 